\title{
Student Response Systems in a Technology Enhanced Flipped Classroom: A Qualitative Investigation in Higher Education
}

\author{
Sebastian Åhman \\ Department of Informatics, Linnaeus University, Växjö, Sweden \\ https://orcid.org/0000-0002-6601-5243 \\ Jonny Nguyen \\ Department of Informatics, Linnaeus University, Växjö, Sweden \\ https:// orcid.org/0000-0002-5119-4883 \\ Naghmeh Aghaee \\ Department of Informatics, Linnaeus University, Växjö, Sweden \\ https://orcid.org/0000-0001-5949-8905 \\ Kevin Fuchs \\ Faculty of Hospitality and Tourism, Prince of Songkla University \\ Phuket, Thailand \\ https:// orcid.org/0000-0003-3253-5133
}

\begin{abstract}
Disruptive technology and a generation with an increased interest in using that technology to aid their learning has caused a need to change the current educational landscape. Student Response Systems are a contemporary means to integrate digital technology in the modern classroom. The purpose of this qualitative study is to examine the perspectives that impact students' engagement when using Student Response Systems in a technology enhanced classroom environment. The study was guided by qualitative methods of inquiry through nonparticipant observations, examination of the course material, and semistructured interviews. The in-depth interviews $(n=14)$ were conducted with graduate students who participated in the technology enhanced flipped classroom (TEFC) during their STEM degree studies in southern Sweden. The collected data were analyzed through the means of content analysis. The results of the study show that Student Response Systems are an effective and innovative method to increase students' engagement in the classroom and embrace a modern learning environment. The participants expressed a positive impact on their willingness to participate in classroom discussions and share their respective views. A drawback that was mentioned is the dissatisfaction to invest more time in preparation ahead of the discussion, compared to lecture-based learning.
\end{abstract}


The Student Response Systems increased the graduate students' esteem to comfortably engage in classroom discussions and offers educators an additional tool to enhance their current pedagogical methods. The study contributes to the body of knowledge by closing an identified research gap that lacks perceptions from graduate students in a STEM program in southern Sweden. There are a few limitations that the reader should consider. The collected data pertains to graduate-level studies in a STEM degree program. Further, ample data were collected through multiple sources; however, the reflections are limited to 14 interview participants and are, therefore, not generalizable to other populations than those examined in the context.

Keywords: Active learning; flipped learning; student response systems; technology enhanced flipped classroom

\section{Introduction}

Traditionally, teaching in higher education has taken a teacher-centered approach, with lecturers delivering classes and students performing out-of-class activities (Fuchs, 2021). Fuchs (2021, p. 18) further stated that "under this traditional approach, the main actor in the teaching-learning process is the lecturer, while students play a passive role". He argued that because of new educational technologies and pedagogical approaches, the scope and impact of web-based learning in higher education have expanded in the recent decade (Fuchs, 2021). The technology enhanced flipped classroom (TEFC) promotes the students' role as the focus of the learning environment and encourages active learning. Moreover, the growth of technology has a footprint in the 'net generation', which refers to students born in or after 1982. Chicioreanu and Amza (2018) stated that the characteristics of the net generation, compared to prior generations, is that they perceive the Internet as a support tool in their studies.

Furthermore, the net generation gravitates towards group activity and is well versed in the use of technology, also referred to as technology enhanced learning (TEL), for information gathering and communication with their peers. Another characteristic is that the net generation is always on the move, demanding adaptable approaches in the use of information and communication technologies (ICT) to satisfy their needs (Chicioreanu \& Amza, 2018; Gokbulut, 2020). The technology enhanced flipped classroom approach intends to challenge the traditional teaching methodologies by having the student access the materials outside of the classroom. This approach aims to prepare students for in-class discussions and encourages active learning during the lecture. According to Murillo-Zamorano et al. (2019), the technology enhanced flipped classroom approach increases students' engagement in the classroom, while providing students the opportunity to review the materials repetitively.

Wang (2017) claimed that the challenges of implementing the flipped classroom approach can be classified into internal and external challenges. The former involves a lack of time, support, and/or resources. In contrast to these internal challenges, the external challenges are not limited to, but include, the attitude of the students, their level of confidence, and cultural beliefs. The majority of studies 
(Wang, 2017; Pinna et al., 2019; Murillo-Zamorano et al., 2019; Fuchs, 2021) concluded that the flipped classroom has a positive effect on students' level of engagement, knowledge development, and cognitive skills. Student Response Systems (SRS), as part of TEL, aim to enhance students' active participation in a flipped classroom (Abeysekera \& Dawson, 2014). A reoccurring claim is that active learning pedagogies require more time in preparing for a lecture, as opposed to a traditional classroom setting (Fuchs, 2021).

Limited research exists that has examined the use and influences of the new generation of SRSs, which have significantly expanded functionality and positive impacts (Mayhew et al., 2020; Gokbulut, 2020). A lack of sufficient literature addressing the shortcomings of students' perception of SRS in the flipped classroom led to the identified gap in the literature. The research gap can be filled by studying and highlighting the students' active participation in an ongoing flipped classroom that uses TEL and engages SRS, in an effort to help students reach the desired learning outcomes.

The rationale of the research is to investigate if TEL, such as SRS, can enhance a university lecture by using the flipped classroom approach, with increased active participation and influence by the students. Furthermore, the research is guided by the following research questions:

(Q1) How do graduate students perceive the usefulness of SRS during their TEFC experience?

(Q2) To what extent can SRS facilitate students' participation in TEFC discussion sessions?

\section{Literature Review}

\subsection{Interaction theory in blended learning}

The blended learning approach establishes a synchronous and asynchronous learning environment by using ICT to mediate information and face-to-face learning methodologies (Çardak \& Selvi, 2016; Rasheed et al., 2019). Rasheed et al. (2019) argued that blended learning is believed to be the most popular and effective educational approach due to its perceived effectiveness in providing flexible and continuous learning opportunities. The approach offers the benefit of increasing interaction between teachers and students. Çardak and Selvi (2016) claimed that the learners have to participate in course activities and realize three types of interaction: student-student, student-teacher, and student-content. Furthermore, Çardak and Selvi (2016) stated that solely designing the course activities to induce interactivity will not necessarily guarantee a higher level of interaction. Therefore, it is important to link the implementation of classroom activities to specific learning outcomes, based on good practices and established methods (Owusu-Agyeman \& Fourie-Malherbe, 2019).

The original concepts of three types of interaction and its model were developed by Anderson (2008, p. 58), which is a development of the original idea described by Moore (1989). The three types of interaction were the core concept of facilitating learning process in different environments. Student-content refers to how students access and interact with the course content to increase the students' 
knowledge. According to a recent study by Kumar et al. (2021, p. 2), the impact of student-content interaction "contributes predominately towards the successful realization of the expected learning outcomes", compared to other types of interaction. Moreover, Çardak and Selvi (2016) argued that student-content interaction is the only type of interaction that affects the students' satisfaction relative to their performance.

Student-teacher interaction aims to increase students' knowledge through dialogues between the student and the teacher and is essential when considering how to enhance students' learning outcomes and perceived satisfaction (Anderson, 2008; Çardak \& Selvi, 2016; Kumar et al., 2021). Park (2015) found that a lack of facilitation can influence the quality of the learning process, and that students might perceive themselves as isolated, which may affect their interactivity level. Therefore, the teachers' role is to motivate and encourage the students by actively involving them in the discussion (Park, 2015).

Lastly, the student-student (peer) interaction refers to increasing students' knowledge through the collaboration between students (Anderson, 2008). Çardak and Selvi (2016) expounded that student-student interaction influences the overall learning outcome. In a study with undergraduate students, Kurucay and Inan (2017) reported that student-student interactions do not affect students' satisfaction. However, group activities are perceived positively to learning and achievement. The addition of TEL requires students to possess specific skill sets, including self-regulation and technological competencies, due to the independence of their instructor outside of the classroom (Kurucay \& Inan, 2017). Furthermore, a prerequisite for blended learning, along with the use of TEL, requires the teacher to possess technological competencies and teaching methodologies (Rasheed et al., 2019).

\subsection{The technology-enhanced flipped classroom}

The flipped classroom approach is grounded in the constructivist theory of learning. It aims to challenge the traditional academic approach of how students make a first contact with the subject, switching from inside to the outside of the classroom's boundaries (Lewis et al., 2018). Abeysekera and Dawson (2014) highlighted the differences in acquiring knowledge between the technology enhanced flipped classroom and the traditional learning approach. In the innovative TEFC approach, the students access the assigned learning material outside the classroom (i.e. pre-class stage) to form their own opinion and knowledge. Afterward, the students attend the classroom (i.e. in-class stage) with their newly formed opinions and acquired knowledge to discuss the topic with their peers and teacher. Therefore, the students might construct their knowledge upon interaction with the lecturer and other students.

Students are then tasked with take-home assignments to apply what they have learned independently; this stage is also referred to as post-class (MurilloZamorano et al., 2019). Further, Murillo-Zamorano et al. (2019) emphasized the importance of TEL for a successful implementation of the technology enhanced flipped classroom prior to, and after, the in-class discussion. 
The TEFC approach is a suitable fit for application with the blended learning approach, where TEL is vital to enhance students' experience and the impact of the approach. Due to the benefits of portable mobile devices, the learning material can be accessed without the constraints of time and space. This creates a flexible learning environment, wherein the students can organize and devote their time to understand a specific topic better, with additional flexibility (Abeysekera \& Dawson, 2014; Lewis et al., 2018; Murillo-Zamorano et al., 2019).

A case study by Lopes and Soares (2018) supported the claim that knowledge can be acquired outside the classroom through pre-recorded online lectures. Instead, the in-class classroom time can be used to guide and motivate the students within more advanced and difficult concepts. Murillo-Zamorano et al. (2019) stated that the use of pre-recorded lectures gives students the control to pause and replay the content and will permit them to learn at their own pace. Furthermore, MurilloZamorano et al. (2019) highlighted the importance of the in-class stage and implementation of interactive activities (e.g., discussions). Discussions with peers are said to improve active participation and students' learning outcomes under the supervision of a teacher (Murillo-Zamorano et al., 2019). The teachers' role is to facilitate the discussion and encourage the students by assigning activities that provoke discussions. Furthermore, the teachers' questioning skills are needed to elaborate on students' ideas and answers (Buil-Fabregá et al., 2019).

\subsection{Student Response Systems (SRS) in TEFC}

In the digital age, and especially for generation $\mathrm{Z}$ (i.e. students born mid-to-late 1990s and the early 2010s), where technology is a basic living factor, there is a need for educational updates, involving more technology-based and game-based elearning in educational settings, rather than only traditional instruction (Gokbulut, 2020). Turan and Meral (2017) and Gokbulut (2020) argued that students perceived their own performance as improved when using SRS in the classroom, including Kahoot!, which is game-based, and Mentimeter, a nongame-based audience response platform. Furthermore, both authors claimed that SRS have the potential to increase students' interactions and attention in the classroom. Turan and Meral (2017) emphasized that game-based and non-gamebased SRS effects differ in the students' achievement and engagement. However, Gokbulut (2020) argued both kinds of game-bases and non-game-based SRS systems influence positively, although in different ways, on the learning process and the result of students.

Mentimeter is an audience response platform, which facilitates an active and discussion-driven dialogic approaches in teaching, to make the learning process more effective than passive learning methods (Mayhew et al., 2020). This SRS allows direct teacher-learner interaction as one of the most agile platforms, with an instant and inclusive dialogue during teaching sessions (Mayhew et al., 2020; Gokbulut, 2020). Mentimeter allows students to get involved in the learning process via their own digital devices, such as smartphones, computers, and tablets, as it can be accessed using all online devices. This is a method with which the net generation feel most comfortable and is a technology-built system, 
compatible with most or all students' digital literacy skills in higher education. The anonymous nature of Mentimeter removes 'answer anxiety' among students (Skoyles \& Bloxsidge, 2017); this 'answer anxiety' was a phenomenon that was observed during the quiz elements and game-based SRSs, in which some students are unwilling to get involved, fearing their answers may be wrong, when given points in front of their peers.

In contrast, Turan and Meral (2017) showed an increase in students' achievement and participation by using game-based SRS, compared to non-game-based. Göksün and Gürsoy (2019) stated that the competitive nature of the SRS-based game Kahoot! has the ability to stimulate, encourage, and motivate students in a desire to achieve more. A study by Licorish et al. (2018) offered similar findings as Göksün and Gürsoy (2019): that Kahoot! increases peer interactions, and the sense of winning influences the learning outcomes. The reward system proves to have a positive impact on increasing students' motivation due to an immediate acknowledgment after using Kahoot! (Licorish et al., 2018). However, Göksün and Gürsoy (2019, p. 12). also stated that "an extremely competitive environment might have an opposite effect, which leads to negative emotions".

Licorish et al. (2018) and Wang (2017) argued that the wear-off effect for experienced users of Kahoot!, in comparison to novice users, have a minimal effect on the users' engagement and motivation, instead of showing increased boredom due to an excessive use of Kahoot!, where consistency might decrease and affect students' learning ability. Fuller and Dawson (2017) emphasized that a teacher must be prepared to use educational technologies, otherwise, the outcome will lead to unsatisfactory results by misusing SRS. SRS allow a teacher to show a set of questions onto the screen, to which the students should respond through a connected device. The instant real-time feedback capability supports the students' needs, and the teacher has the ability to assess the students' understanding of the assigned materials and concepts in real-time (Licorish et al., 2018). Turan and Meral (2017) highlighted that reading a text, followed by a test, improves information retention in contrast to repetitively rereading a text. Wang (2017, p. 7) described a drawback of SRS as "students who skip reading the assigned tasks, could negatively affect the classroom experience due to their fear of answering the questions incorrectly".

\subsection{Active learning as a facilitator of constructivism}

The constructivism theory, opposed to the instructivism theory, is a studentcentered learning approach; this refers to supporting learners' initiative, in contrast to the traditional learning approach, where the learners are passive recipients of information ( $\mathrm{O}^{\prime}$ Connor, 2020; Mintzes, 2020). Constructivists argue that learning is based on constructing new knowledge of the students' prior experiences, which can be achieved through social interactions (Mintzes, 2020). The role and responsibility of teachers in a constructivist-learning environment differ from the traditional learning approach. Teachers are seen as facilitators, rather than instructors, and are expected to create a collaborative problem-solving environment to involve students (Aljohani, 2017; Mintzes, 2020). 
Furthermore, according to a study by O'Connor (2020), active learning is explained as a method and set of procedures that support students in their education through actively involving and engaging them. The students' prior state of knowledge is set as their personal standard. The teachers can adjust the level of their involvement during the lecture in response to the students' performance and participation (Mintzes, 2020). O'Connor (2020) argued that the current western society requires specific skillsets from the student that are more complex to achieve using traditional learning approaches, in which the student acts as a passive recipient. Hence, students need to actively participate during a lecture to apply their present knowledge to solve complex problems more innovatively and creatively (Aljohani, 2017; O'Connor, 2020).

\section{Methodology}

\subsection{Sample}

To examine how students perceive the use of SRS in TEFC, the following qualitative research method was utilized. The data were collected through three separate in-class observations that allowed the authors to gather initial data and as a guide to compile the open-ended questionnaire. Furthermore, semistructured interviews were conducted with graduate students in a STEM subject. The interviews were conducted virtually due to the increasing threat of COVID19 at the time. The sample size represented $20 \%$ of the total population based on student enrollment in the graduate course that used the flipped learning pedagogy. The students were enrolled at Linnaeus University in the south of Sweden. Moreover, the participants were randomly selected and invited to participate in the interviews (Table 1).

Table 1: Socio-demographic profile of the interview participants

\begin{tabular}{llc} 
Characteristics & Absolute \\
\hline Gender & Male & 7 \\
& Female & 7 \\
Age Range & Others & - \\
& $20-29$ years of age & 3 \\
Highest Academic Degree & 30 - 39 years of age & 7 \\
& Vocational Degree & 4 \\
& Bachelor's Degree & - \\
& Master's Degree & 7 \\
& Philosophical Doctorate & 6 \\
Type of Student ${ }^{1}$ & Other Degree & 1 \\
Years in Higher Education $^{*}$ & Campus Student & 7 \\
& Distance Student & 7 \\
& 3 years or less & - \\
& 3 - 5 years in total & 6 \\
& 6 - 9 years in total & 4 \\
& 10 years or more & 4 \\
\hline
\end{tabular}

${ }^{1}$ The course was offered as a hybrid model allowing campus-based students as well as distance students to participate in the course simultaneously 


\subsection{Data Collection}

Fourteen semi-structured interviews were conducted through online video conferencing to collect the necessary data, to examine the perspectives of graduate students concerning the use of SRS in TEFC. The data collection was carried out in the first half of 2020 at Linnaeus University in Sweden at the Faculty of Technology. The primary data collection was preceded by three non-participant observations. The authors were given access to the course material to enhance the quality of the interview questionnaire. Necessary adjustments were made based on the observations and a suitable questionnaire was developed for the semistructured interviews. The length of the interviews ranged from 25 minutes to 55 minutes with an average duration of 42 minutes.

\subsection{Data Analysis}

The method of inquiry through observations and semi-structured interviews suggested a content analysis of the collected data. During the interview, a series of open-ended questions, that aimed to gain a more comprehensive insight into the participants' perspectives, were asked. With the consent of the participants, the interviews were audio-recorded, transcribed verbatim, and categorized according to the questions posed to the participants. Moreover, the transcripts were used only for purpose of content analysis and did not reveal the identity of the participants. The content analysis was developed based on the gathered data from observations and interviews to create themes and subthemes (groups and patterns), through analyzing, bundling and grouping sets of data clusters, information, and the developed codes.

\subsection{Ethics}

For the observations, verbal consent was obtained at the beginning of the classes that were attended by the researchers and the wider scope of the research was introduced. However, few details were revealed to avoid causing bias in the study. The observers focused on the aim of the study, and other learning objectives in the course were ignored. Confidentiality and data privacy were considered and guaranteed. The interview participants were presented with the specific aim and scope of the research, and oral consent was obtained through recording their agreements before conducting the interviews. The consent form was developed in accordance with the policies of the Ethical Advisory Board in South East Sweden (2021). Furthermore, confidentiality was extended to all 14 participants of the interviews, and only the researchers knew their identity.

\section{Results}

During the first of the three observations, the authors witnessed that a handful of students did not prepare for the lecture (i.e., students ignored the pre-class stage and proceeded directly to the in-class stage). The students' engagement strongly varied from passive to active participants. It was noted that most of the students did not actively participate during the discussion. Another observation was that the active students seized the opportunity to control the discussion amongst themselves. This made it even more difficult for passive students to participate and engage in the discussion. These observations helped the authors to develop the open-ended questions for the subsequent interviews with the participants. 
Later, all the interview participants commented that this course was their first experience with the TEFC concept. Most of the students noted that they liked the TEFC concept because it was a more innovative way of learning. Moreover, they attested an interest in getting the information beforehand, which allowed them to prepare for the in-class discussion. Therefore, it helped the students to be better prepared and provided them with a better general understanding of the topic at hand as shown by a representative comment (P2):

"For me, it was new and more interesting, because you tend to go into the class having some information beforehand. If there is a gray area, you can go prepared with questions. It forms some sort of clarity. Even if you study and you do not really understand, and you get to class, you tend to have a better understanding of the subject" [P2]

Furthermore, a few students showed their interest in the TEFC approach because it gave them an opportunity to immerse and understand the subject better. Moreover, it helped the students who disregarded the pre-class stage previously to better comprehend and gain clarity on the topic despite the lack of spending time on the pre-reading material. The students claimed that it was easier to follow a peer discussion for comprehension than reading the material themselves or attend a traditional lecture-based class. One participant commented positively about the flexibility to openly discuss and exchange ideas to further learn from each other in the classroom. Another participant agreed, but added that the shortcoming with the TEFC approach was the information gathering in the preclass, because it was perceived as one-way learning without much peer interaction or student-teacher interaction (P1). However, another concern addressed by a participant was that the in-class discussion could become lengthy, and shift focus away from the original topic.

"I am not very keen on the flipped classroom concept. I would say halfhalf because watching the lecture beforehand it is a one-way thing" [P1]

The participant stated that learning outside of the classroom, without a tutor, might lead to misinterpretation of the materials, because they were not able to ask questions of the teachers. Moreover, the majority of the participants attested a preference with the learning management system (LMS) called Moodle. Moodle facilitates pre-class and post-class learning material, accessible in a cloud-based system. Participants commented that the embedded notification system is particularly well received and beneficial, as it informed them of any updates on the course without the need to check the LMS. A statement by P2 is illustrative for the majority of the participants who pointed out that a direct link between their LMS and the virtual library would be beneficial and would improve their user experience (the virtual library of the university facilitates the digital storage of scientific literature).

"I would not say it was difficult (to find), every material was already provided. You know with the digital library, I find it easier to find whatever material was recommended [...] as long as the title was available, the library had access to the material, it was not difficult to find". [P2] 
During the second and third observation sessions with the use of SRS, the researchers observed an increase in students' motivation to participate. Furthermore, the researchers observed that most students appeared to be unfamiliar with the use of SRS. Here, the researchers suggested that the course instructor uploaded a video that would explain the usage of SRS in the context of the flipped classroom. However, this drawback was not perceived as significant, and most students were able to appreciate the use of SRS. Moreover, another noteworthy observation was that some students took notes during the in-class discussion, reflecting upon other students' responses to facilitate their learning process.

Most of the participants perceived some benefit in the use of SRS. They elaborated that these tools had a positive impact on their participation in the classroom. Furthermore, SRS seemed to influence the students' learning outcomes by reinforcing their perceived knowledge. Most of the participants stated that Kahoot! and Mentimeter were easy to use, and they had no problem adopting these technologies. There was no consensus amongst the participants which tool was better suited for their learning. Some participants shared that the use of SRS supported their participation, and it also motivated them to prepare for the discussion (i.e., in-class stage). Based on this finding, it can be noted that SRS had a positive impact on their willingness to prepare for the discussion with their peers and be more inclined to use the pre-class learning material.

"Using Mentimeter or Kahoot! will encourage people to participate in the classroom more. It will help them to brainstorm. Using Kahoot! is kind of fun using in the class. It also helps people to prepare themselves before coming to class by reading the materials" [P3]

Another advantage of using SRS, according to the participants, is that it eliminates the risk that some participants cannot join the in-class discussion and hence reduces the feeling of being left out. Some participants who consider themselves less talkative added that TEL helps all students and gives them a chance to voice their opinions through TEL. However, the participants also commented that one of perceived issues is that even though the answer is known to the participant, due to the personality trait of the participant, the participant might reconsider sharing their thoughts and opinion openly. Therefore, the participant might share the same view as the majority of the students in the classroom, in which the use of SRS might reinforce students' participation and remove bias. Although most students agreed that Kahoot! is pleasurable to use, some students had a contrasting opinion. They claimed that Kahoot!, with its competitive elements, had a negative impact due to not measuring real performance.

A participant noted that the way Kahoot! measures performance based on a combination of speed and knowledge, whereas the participant stated that performance should not be measured by speed. The majority of the participants stated that they were interested to familiarize themselves with the new technology (i.e., SRS) and to prepare before using it inside the classroom. The students also highlighted that classroom time is precious and should be used effectively, including reducing students' confusion at the beginning of the in-class stage. 


\section{Discussion}

The empirical findings of this study indicate that all the participants had their first experience with the TEFC concept during the examined course. The participants perceived it as an innovative way to acquire new knowledge in contrast to prior experiences that were lecture-based. This implies that this new learning methodology is perceived as more beneficial to students' learning outcomes, as claimed in similar case studies (Lopes \& Soares 2018; Chen \& Relan 2018; MurilloZamorano et al., 2019). Furthermore, the participants highlighted that the TEFC approach allows them to better prepare and immerse themselves within the subject before the discussion session, implying that other sources may be used to study a subject in-depth.

The lack of familiarity with the TEFC concept might lead to a different view compared to students who are experienced with the TEFC concept (Abeysekera \& Dawson 2014; Lewis et al. 2018; Murillo-Zamorano et al., 2019). The formerly mentioned studies highlight the need to shift the learning environment in the classroom, switching from inside to outside the classroom boundaries, to better prepare students before a class. Murillo-Zamorano et al. (2019) argued that a flexible environment enables students to devote their time to understand a topic better. The observed learning environment indicates a flexible learning environment, as described by Murillo-Zamorano et al. (2019), wherein the students are in focus and take responsibility for their learning.

Furthermore, the TEFC approach requires both teachers and students to possess additional skillsets and competences, such as digital literacy. As earlier studies (Skoyles \& Bloxsidge, 2017; Turan \& Meral, 2017; Licorish et al., 2018; Mayhew et al., 2020; Gokbulut, 2020) noted, the study's results also show that different types of SRS are positive to facilitate active learning in the discussion sessions and lectures. The students' reflections were positive toward both game-based and non-game-based SRS, but in different ways. Kahoot!, used as a quizzing system, facilitated learning through competitions; however, using audience response platform Mentimeter, facilitated the anonymous voice and more freedom to answer the questions freely, specially by removing answer anxiety among students (Skoyles \& Bloxsidge, 2017).

The participants' willingness to prepare for a lecture mostly derived from the inclass discussion. The possible disadvantages are the lack of additional incentives for participants to prepare for an open discussion, and the discussions going off topic without a good facilitator steering it in the right direction. However, these shortfalls are no less of a drawback than students who refuse to study during a lecture-based class. Furthermore, the empirical findings highlight the issue with the amount and difficulty of understanding of some of the assigned materials. Participants argued that their academic background might help them follow a specific topic easier. However, the role of SRS in-class and the way of students' involvement and active participation may also help them to follow and learn about a specific topic. According to the participants, another consideration is the amount of the assigned materials, including videos and academic literature, in pre-class. The participants perceive that too much learning materials might affect 
their understanding of a topic because they did not manage to finish the assignments in time. According to prior studies (Abeysekera \& Dawson 2014; Lewis et al., 2018), constructivism is based on constructing new knowledge through prior knowledge and experiences.

Göksün and Gürsoy (2019) claimed in their study that the constructivists' worldview sets the students' previous state of knowledge as standard. It would be beneficial to the students learning if the teachers adjust their involvement accordingly and support the students in their learning. Göksün and Gürsoy (2019) argued that teachers need to select activities and relevant materials to the subject to stimulate active learning. The empirical findings indicate the importance of students' prior knowledge and experience in connection to the material and the types of questions in the discussion sessions. The observed setting suggests that prior knowledge and academic background affect the students' acquisition of new knowledge, due to a higher threshold and lack of essential knowledge. In addition, the study implies that it impacts the time that is needed to understand the assigned materials. However, going through the material in the discussion sessions (in-class) and using SRS to motivate students to have outputs and not just input from the course, would also influence learning processes.

Another advantage of using SRS is that teachers could assess the students' prior knowledge level beforehand, as well as their understanding and learning by getting their feedback, so as to adjust the topics' difficulty level accordingly. Otherwise, the students may fail in contributing to their learning and participation during class. SRSs facilitate active and discussion-driven dialogic approaches in teaching, to make the learning process more effective (Mayhew et al., 2020) and, as the result shows, more relevant and connected to students knowledge and background, so as to learn the materials easier and faster. Students' reflection on SRSs allows direct teacher-learner interaction (as also mentioned by Gokbulut, 2020), as one of the most agile systems of having learning iterations and getting direct feedback in a TEFC setting.

The results of this study show that the teachers' role, the use of SRSs, and the chosen teaching strategies and adjustments have a direct link to students' engagement when using technology in the classroom. An appropriate amount of assigned materials and relevant group activities need to be selected accordingly to induce students' engagement. Finally, the perceived factors have the potential to increase students' willingness to participate during lectures, as part of the inclass discussion and, therefore, it can be concluded that SRS has a positive impact on students' learning, keeping in mind the drawbacks that were mentioned.

The findings imply that students are willing to learn on their own (in pre-class) and perceive their participation as an important factor to construct new knowledge during in-class discussions. Nevertheless, some of the students feel obligated to involuntarily participate in the discussion to get activity points (that are relevant for their grades). One disadvantage of having obligatory participation is that the students' stress and anxiety levels could increase (Abdullah et al., 2021) and, therefore, negatively affect their willingness to participate during the 
discussion. However, using audience response systems, such as Mentimeter, and its anonymous nature of involvement in the discussions, may help motivate students to participate, by removing answer anxiety (Skoyles \& Bloxsidge, 2017). Less stress and anxiety to give an answer in front of peer students and teachers would make active learning possible. Anonymous applications, as compared with an open discussions in-class or the game-based SRS, such as Kahoot!, may students' involvements more comfortable.

The empirical finding is further supported by the constructivist viewpoint, in which prior studies can be constructed upon prior knowledge. Çardak and Selvi (2016) claimed that students' interaction with their peers might influence and enhance students' learning outcomes. This was also confirmed by the participants, that getting involved in the discussions in-class, in connection to what they have learned from pre-class, would affect their learning process and outcomes more efficiently. Moreover, the quality of the discussions and students' answers and feedback (through SRSs) may help teachers to adjust the level of the discussion and guide students to learn the materials, in the best way.

This study shows that different types of SRSs may be beneficial in many different aspects of teaching and learning process, when combined with the TEFC environment. The students perceive it as an innovative way to enhance and facilitate the current modern learning environment. The results show that factors that influence students' engagement when using technology include a shift of learning methodology. Ultimately, the students are responsible for their learning and adequate competition between peers. Moreover, the results indicate that SRS facilitate and support students in sharing their opinions and experiences with the class. In addition, the results show that the use of open-ended questions, compared to quiz-based questions approach, has a more significant impact in achieving active participation, for this group of students and in this learning setting. The use of SRS and anonymity of the answers would motivate an initiation of discussions and sharing opinions, while teacher and peer acknowledgment would also help students to feel more assured and comfortable when participating in the game-based SRS or class discussion in-class. Therefore, SRSs would increase the students' willingness to participate and involve actively in the class discussions in the TEFC environment.

\section{Conclusion}

This study aimed to investigate what factors influence students' engagement to become independent and active learners in TEFC setup, and if SRS can facilitate and increase students' active participation and engagement when using technology to enhance the flipped classroom strategy. The result of this shows that by using the SRS in the TEFC discussion sessions, more specifically for the open-ended questions approach, getting quizzes, and SRS initiation of discussions and different types of interaction was perceived positively. It supports student in contemplating and assessing their knowledge before answering questions (to support student-content interaction), which induces active learning. The quizbased questions approach was perceived to increase student engagement by applying fair competition and increasing the students' willingness to prepare for 
the discussions and perform better with their peers (to support peer interaction). The system of getting feedback on students' knowledge and understanding on the materials, and providing opportunities for teachers to adjust, guide, and supervise the discussions on the right direction and in-line with the course materials and learning outcomes, is the last positive influence of using SRS in TEFC settings. Therefore, both aspects of technology used in TEFC approach helped to motivate the students to prepare better for the lectures and perform better in class. In conclusion, SRS were perceived to have a good impact on students' attention and overall participation and learning. Therefore, this study recommends the use of SRS in different ways, to facilitate students' active participation and engagement, as well as to develop their interaction and learning in the TEFC (technology enhanced flipped classroom) learning environment.

\section{Limitations and Future Works}

While this study contributed to the body of knowledge, the authors acknowledge the limitations of this study and the lack of generalizability of results to settings. Therefore, it should be noted that the results of this study should be interpreted in the context of the parameters that were stated. The results of the study are consequently limited to graduate students in southern Sweden. Moreover, the reader is advised to consider the limited sample size $(n=14)$ and the amount of non-participatory observations $(n=3)$. To investigate the research area further, a study with a larger sample would increase the reliability and validate the results. A quantitative inquiry has the potential to achieve generalizability to a larger population in a broader context and would therefore further contribute to the research area and body of knowledge. Another recommendation for future studies is to combine the observations with the interviews to investigate if the perceived usefulness is in line with what was observed, that is, pre-observation followed by interviews and concluded by another round of observations.

\section{Acknowledgments}

\subsection{Recognition}

The authors would like to thank the participants who allowed the researchers to observe their classroom sessions. In particular, the researchers would like to thank the participants who shared their experiences through the semi-structured interviews.

\subsection{Conflict of Interest}

The authors would like to declare that co-author N.A. was involved as a lecturer in the course that was used for the empirical data gathering of this study. Furthermore, the authors would like to declare no potential conflicts of interest concerning the research, authorship, and/or publication of this article. The empirical data collection originated and derived from two theses: A Bachelor's thesis by the co-authors S.A. and J.N. and a Master's thesis by the co-author K.F., under the supervision of N.A. for both theses.

\subsection{Funding}

No funding was received for the research project reported in the article. 


\section{References}

Abeysekera, L., \& Dawson, P. (2014). Motivation and cognitive load in the flipped classroom: definition, rationale and a call for research. Higher Education Research \& Development, 34(1), 1-14. https:// doi.org/10.1080/07294360.2014.934336

Abdullah, M., Hussin, S., \& Ismail, K. (2021). Does Flipped Classroom Model Affect EFL Learners' Anxiety in English Speaking Performance? International Journal of Emerging Technologies in Learning, 16(1), 94-108. https://www.learntechlib.org/p/218651/

Aljohani, M. (2017). Principles of "constructivism" in foreign language teaching. Journal of Literature and Art Studies, 7(1), 97-107. https://doi.org/10.17265/21595836/2017.01.013

Anderson, T. (Ed.) (2008). The theory and practice of online learning. Athabasca University Press.

Buil-Fabregá, M., Martínez Casanovas, M., \& Ruiz-Munzón, N. (2019). Flipped classroom as an active learning methodology in sustainable development curricula. Sustainability, 11(17), 4577. https:// doi.org/10.3390/su11174577

Çardak, Ç. S., \& Selvi, K. (2016). Increasing teacher candidates' ways of interaction and levels of learning through action research in a blended course. Computers in Human Behavior, 61(1), 488-506. https://doi.org/10.1016/j.chb.2016.03.055

Chicioreanu, T. D., \& Amza, C. G. (2018). Adapting Your Teaching to Accommodate the Net Generation/Z-Generation of Learners. eLearning \& Software for Education, 3(1), 13-20. https://doi.org/10.12753/2066-026X-18-143

Ethical Advisory Board in South East Sweden. (2021). Advice and ethical assessment of projects. https://lnu.se/en/meet-linnaeus-university/collaborate-withus/projects-and-networks/ethical-advisory-board-in-south-east/

Fuchs, K. (2021). Innovative Teaching: A Qualitative Review of Flipped Classrooms. International Journal of Learning, Teaching and Educational Research, 20(3), 18-32. https://doi.org/10.26803/ijlter.20.3.2

Fuller, J. S., \& Dawson, K. M. (2017). Student response systems for formative assessment: Literature-based strategies and findings from a middle school implementation. $\begin{array}{llll}\text { Contemporary Educational } & \text { 374), }\end{array}$ https://doi.org/10.30935/cedtech/6206

Gokbulut, B. (2020). The effect of Mentimeter and Kahoot applications on university students' e-learning. World Journal on Educational Technology: Current Issues, 12(2), 107-116. https://doi.org/10.18844/wjet.v12i2.4814

Göksün, D. O., \& Gürsoy, G. (2019). Comparing success and engagement in gamified learning experiences via Kahoot and Quizizz. Computers \& Education, 13(1)5, 1529. https://doi.org/10.1016/j.compedu.2019.02.015

Kumar, P., Saxena, C., \& Baber, H. (2021). Learner-content interaction in e-learning - the moderating role of perceived harm of COVID-19 in assessing the satisfaction of learners. Smart Learning Environments, 8(1), 1-15. https:/ / doi.org/10.1186/s40561021-00149-8

Kurucay, M., \& Inan, F. A. (2017). Examining the effects of learner-learner interactions on satisfaction and learning in an online undergraduate course. Computers $\mathcal{E}$ Education, 115(1), 20-37. https:// doi.org/10.1016/j.compedu.2017.06.010

Lewis, C. E., Chen, D. C., \& Relan, A. (2018). Implementation of a flipped classroom approach to promote active learning in the third-year surgery clerkship. The American Journal of Surgery, 215(2), 298-303. https:// doi.org/10.1016/j.amjsurg.2017.08.050 
Licorish, S. A., Owen, H. E., Daniel, B., \& George, J. L. (2018). Students' perception of Kahoot!'s influence on teaching and learning. Research and Practice in Technology Enhanced Learning, 13(1), 1-23. https:// doi.org/10.1186/s41039-018-0078-8

Lopes, A. P., \& Soares, F. (2018). Perception and performance in a flipped Financial Mathematics classroom. The International Journal of Management Education, 16(1), 105-113. https:// doi.org/10.1016/j.ijme.2018.01.001

Mayhew, E., Davies, M., Millmore, A., Thompson, L., \& Pena, A. (2020). The impact of audience response platform Mentimeter on the student and staff learning experience. Research in Learning Technology, 28. https:// doi.org/10.25304/rlt.v28.2397

Mintzes, J. J. (2020). From constructivism to active learning in college science. In J. Mintzes \& E. Walter (Eds.), Active Learning in College Science (pp. 3-12). Springer. https://doi.org/10.1007/978-3-030-33600-4_1

Murillo-Zamorano, L. R., Sánchez, J. Á. L., \& Godoy-Caballero, A. L. (2019). How the flipped classroom affects knowledge, skills, and engagement in higher education: Effects on students' satisfaction. Computers \& Education, 141(1), 103608. https://doi.org/10.1016/j.compedu.2019.103608

Moore, M. (1989). Three types of interactions. American Journal of Distance Education, 3(2), 1-7. https://doi.org/10.1080/08923648909526659

O'Connor, K. (2020). Constructivism, curriculum and the knowledge question: tensions and challenges for higher education. Studies in Higher Education, 1-11. https://doi.org/10.1080/03075079.2020.1750585

Owusu-Agyeman, Y., \& Fourie-Malherbe, M. (2019). Negotiating co-ownership of learning in higher education: an underexplored practice for adult learning. Studies in Continuing Education, 41(1), 17-35. https://doi.org/10.1080/0158037X.2018.1497591

Park, J. Y. (2015). Student interactivity and teacher participation: an application of legitimate peripheral participation in higher education online learning environments. Technology, Pedagogy and Education, 24(3), 389-406. https:// doi.org/10.1080/1475939X.2014.935743

Pinna, G., Mena, J., \& Funes, S. (2019). Undergraduate students' perceptions about the use of Kahoot! as part of the Flipped Classroom methodology. Proceedings of the Seventh International Conference on Technological Ecosystems for Enhancing Multiculturality (pp. 619-625). ACM Digital Library. https:// doi.org/10.1145/3362789.3362900

Rasheed, R. A., Kamsin, A., \& Abdullah, N. A. (2020). Challenges in the online component of blended learning: a systematic review. Computers $\mathcal{E}$ Education, 144(1), 103701. https://doi.org/10.1016/j.compedu.2019.103701

Skoyles, A., \& Bloxsidge, E. (2017). Have you voted? Teaching OSCOLA with Mentimeter. Legal Information Management, 232-238. https://doi.org/10.1017/S1472669617000457

Turan, Z., \& Meral, E. (2018). Game-Based versus to Non-Game-Based: the Impact of Student Response Systems on Students' Achievements, Engagements and Test Anxieties. Informatics in Education, 17(1), 105-116. https://doi.org/10.15388/infedu.2018.07

Wang, T. (2017). Overcoming barriers to 'flip': building teacher's capacity for the adoption of flipped classroom in Hong Kong secondary schools. Research and Practice in Technology Enhanced Learning, 12(1), 1-11. https://doi.org/10.1186/s41039-0170047-7 